\title{
Ridículo político: análisis de una mutación estético-política.*
}

\author{
Political ridicule: analysis of an aesthetic-political mutation
}

\author{
Por: Tiburi, Marcia* \\ Universidad de París 8
}

Francia

http://orcid.org/0000-0002-0940-5835

Email: marciatiburi2011@gmail.com

Fecha de recepción: 24/08/2020

Fecha de aprobación: 31/10/2020

DOI: http://dx.doi.org/10.30972/nvt.1624538

\section{Resumen}

El término Ridículo Político designa una mutación a gran escala en la cultura política. La hipótesis de este artículo es que esta mutación se establece a un nivel estético fundamental para la política. Lo trágico como fundamento de lo político fue reemplazado por lo cómico. Otra hipótesis a analizar es que la transición al fascismo hoy se ha producido mediante el uso metodológico del "ridículo político" transformado en capital, especialmente en procesos electorales marcados por el populismo. Por tanto, el artículo propone introducir el concepto de burla a través de un análisis de lo risible como forma psicopolítica de control y catarsis social.

\footnotetext{
*El concepto de "Ridículo Político" fue presentado en el libro del mismo nombre publicado en 2017 por Ed. Record. En este artículo, presento los aspectos planteados en la continuación de la investigación sobre el tema. Revisión del texto por Ariel Lugo.

* Graduada em Filosofia pela Pontifícia Universidade Católica do Rio Grande do Sul (1991), graduação em Artes Plásticas pela Universidade Federal do Rio Grande do Sul (1996), mestre em Filosofia pela Pontifícia Universidade Católica do Rio Grande do Sul (1994) e doutora em Filosofia pela Universidade Federal do Rio Grande do Sul (1999) com ênfase em Filosofia Contemporânea. Pós-doutorado em Artes pelo Instituto de Artes da UNICAMP. É professora do curso de filosofia da Universidade Federal do Estado do Rio de Janeiro (UNIRIO). Temas de interesse: filosofia contemporânea, filosofia da linguagem, ética, estética, biopolítica e feminismo.
} 
Ridículo político: análisis de una mutación estético-política.

Palabras clave: Ridículo; Estética; Política; Tragedia; Cultura política.

\begin{abstract}
The expression Political Ridicule designates a mutation in political culture on a global scale. This article hypothesizes that this mutation is establishing at an aesthetic level fundamental to politics. The tragic was the basis of politics and comic replaced it. Another hypothesis to be analyzed is that the passage to fascism today has occurred through the methodological use of "political ridiculousness" transformed into capital, especially in electoral processes marked by populism. The article proposes, therefore, to introduce the concept of ridicule through an analysis of laughable as a psychopolitical form of control and social catharsis.
\end{abstract}

Keywords: Ridiculous; Aesthetics; Politics; Tragedy; Political culture.

\title{
Cómo citar este artículo:
}

APA: Tiburi, M (2020) Ridículo político: análisis de una mutación estético-política. Nuevo Itinerario, 16 (2), 217-239. Recuperado de: (agregar dirección web)

1. La hipótesis del ridículo político

Este trabajo tiene un doble propósito. En primer lugar, situar el concepto de "Ridículo Político" (Tiburi, 2017) como una categoría de análisis válida para la comprensión de la política contemporánea. En segundo lugar, trata de responder a la cuestión del paso de las democracias contemporáneas al fascismo o, en términos más sociales, a la fascistización de las sociedades en nuestra historia política reciente. Desde un enfoque estético-político, la hipótesis sostenida es que el "Ridículo Político" es el operador efectivo y procedimental del giro autoritario que se presenta de manera seductora a las masas en esta fase del capitalismo mundial. El "Ridículo Político" (que, como categoría, implicaría el término ridículo o ridiculización) se ha convertido en el calibrador de un metabolismo estético-político que acompaña a un proyecto económicoideológico. El populismo de extrema derecha en vertiginoso ascenso en la segunda década del 


\section{$\underline{1}$}

Marcia Tiburi

2000 se revela en este proceso no sólo como un astuto usuario de esta dimensión estética marcada por performatividades y teatralidades, sino como la cosa misma.

La expresión "Ridículo Político" se define en la intersección entre los campos de la estética y la política. A través de ella se expone lo que puede considerarse una mutación en la cultura política actual, cuyos avatares más evidentes se encuentran por lo menos cien años antes, en el contexto de los fascismos que se han apoderado de Europa. El tema puede llegar a los albores de la historia del poder, así como tener un vasto alcance geopolítico. A diferencia de una ruptura, la mutación en cuestión está tejida en la historia y se observa en la irrupción decisiva y original del plano estético como tejido fundamental de la experiencia política. En la búsqueda de la verdad que caracteriza a los esfuerzos filosóficos hay que tener en cuenta que la estética no puede separarse de la política, de la misma manera que la política no puede separarse de la estética. En este sentido, trataremos de mostrar cómo la mutación política en juego es en sí misma una mutación estética que no sólo perturba sino que establece otra cualidad de lo político.

También puede decirse que el plan estético, como el carácter plástico de la política, se conforma de acuerdo con las necesidades de los poderes en juego -considerando el juego político en su dimensión competitiva, mimética y teatral- y se destaca más o menos de acuerdo con las situaciones y condiciones históricas. Lo que hoy se llama antipolítica es precisamente la política que se esconde como tal y reaparece como una farsa, pero sólo para aquellos que están en condiciones cognitivo-afectivas de percibir los matices de tal trama. Muchos entran en el juego sin darse cuenta, precisamente porque su percepción está siendo afectada.

El no político o apolítico es uno de los principales tropos retóricos de la antipolítica. Los personajes políticos que se definen como apolíticos ciertamente operan como cínicos a nivel del discurso. Es una astucia utilizada por los candidatos, en tiempos de campaña, que se benefician políticamente de la operación de destrucción genérica de la política. Pronto se desarrollará la cuestión de la diferencia entre lo político (el contexto general de la condición humana, de ser genérico en la acción lingüística e intersubjetiva) y la política (de las instituciones burocratizadas), pero por el momento se intenta poner en escena que la posición paradójica, poco percibida por la población -el electorado-, refleja sobre todo un efecto del poder en la época de su ridiculización. Lo que surge como odio a la política proviene de una degradación de la política operada en su propio tazón. La supresión fetichista de la esencia política de la elección es una de las tácticas comunes en el contexto del abandono de los escrúpulos que 
Ridículo político: análisis de una mutación estético-política.

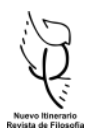

caracterizan la moral de los candidatos y de las masas involucradas en los juegos políticos. El cinismo es la regla de esta discursividad que niega el lugar en el que se pone a sí misma. Ciertamente, el personaje que encarna esta paradoja de ser político mientras niega la política, es tanto más grotesco cuanto más intenta utilizar el efecto del poder. Al mismo tiempo, cuanto más lo niega, más victorioso se vuelve.

En la era de la percepción manipulada, se hace imposible para la mayoría de la población entender el juego que se está jugando, en otras palabras, percibir la actuación en la que participan. Como en el clásico cuento de H. C. Andersen, en el que los súbditos no pueden ver la desnudez del rey, ${ }^{1}$ nos enfrentamos a un grave problema de discernimiento que es, igualmente, de percepción. La imagen del cuento nos pone delante de la cuestión del plano estético-político. Lo que se suprime en lo que Edward Grüner definió como una "supresión fetichista del político por las operaciones de la política" (2002, p. 34) es precisamente la imagen de la desnudez del rey. En otras palabras, impide que se perciba la verdad y su trágica carga. La impresión de prestigio en la política contemporánea proviene de la producción de ilusiones. Esta es la estrategia misma de la política en el contexto del capitalismo. El político, la instancia trágica, desaparece, como veremos más adelante, a través de las operaciones de la política como instancia burocrática.

Ahora hay que prestar atención a la estructura de la supresión relacionada con la política transformada en una operación de ocultación del político. El poder debe ocultar la desnudez del rey, porque su mantenimiento depende de esta ocultación. Sin embargo, no sólo el rey está desnudo, la ropa no existe, y hay que preguntarse cómo desapareció, porque no es un objeto que nunca haya existido. Aunque haya tantos personajes que no lo usen, se guarda en algún lugar.

En el contexto de la argumentación actual, esto significa que la instancia ritual propia del político, en la época de lo trágico, da paso a una mera simulación en la época del cómico. Lo común - el traje que todos debemos ver o cuya ausencia todos debemos percibir- que nace del ritual que, a su vez, designa lo que se hace juntos para celebrar algo, se encuentra vacío. Lo

\footnotetext{
${ }^{1}$ La nueva ropa del emperador fue publicada en 1837 por Hans Cristian Andersen y está inspirada en historias cortas. En este caso, la percepción de un niño que ve al rey desnudo es una metáfora de la conciencia que no se somete a la vanidad y el orgullo del poder.
} 


\section{Marcia Tiburi}

común es la fantasía e incluso el delirio. $^{2}$ Lo que en Kojève (1946) aparece como la "animalización del hombre", el "esnobismo" como un ritual vacío de contenido, como pura formalización de la vida humana, puede ser una clave para entender lo que está pasando. Lo que entendemos por comedia, sobre la que se ha hecho mucha menos teoría que sobre la tragedia hasta hoy, es el lugar político de la época post-histórica de Kojève, en la que el ser humano entraría en un devenir-animal. Ahora bien, la comedia tiene vínculo con el animal rastrero, con lo humano en relación al universo de los seres infernales, en oposición a lo trágico vinculado a la trascendencia, al mundo de los dioses y, por lo tanto, a la muerte.

En este sentido, la mutación de la que trata este artículo se refiere a la elevación del cómico a un nuevo nivel e incluso a un nuevo paradigma político en el que se niega al político mismo, mientras él es lo trágico y, para tener en cuenta lo que nos dice Kojève, lo histórico. Por lo tanto, no hay ninguna utopía en esto, como parece haberla en Kojève cuando da sus impresiones sobre los rituales vacíos de la aristocracia japonesa y el American Way of Life. Es la naturaleza misma en la que la animalización podría significar la reconciliación que se niega en el momento de la farsa. En lugar de la verdad o de la búsqueda del nexo entre la política y la verdad, el ser humano tiene ahora que resolverse a sí mismo por simulacro en el orden político en el que vive. No es de extrañar que los discursos en tono de post-verdad, las Fake News, la desinformación, sean parte de un programa lingüístico producido como una nueva forma de hacer política. La post-verdad sólo pudo surgir en la post-historia de Kojève y representa un nuevo metabolismo de la economía lingüística.

Con este enfoque, la imagen de la política en las condiciones del capitalismo está ciertamente en juego, pero, sobre todo, esa imagen en el contexto de la performatividad política general, en la que los efectos buscados por el capitalismo sirven a la autorreproducción del poder ${ }^{3}$. La operación ritual simbólica propia a todo el poder es lo que llamamos aquí su performatividad, y está vacía. Ahora implica pretender que el poder en sí mismo no está en la escena, que la violencia que se practica en nombre del poder no es violencia. La supresión fetichista del político es también la supresión de la verdad. Al mismo tiempo, se simula un vínculo inmediato entre el pueblo y el carácter soberano o político en la fase electoral a través

\footnotetext{
2 En 2019, publiqué Delírio do poder, psicopoder e loucura coletiva na era da desinformação, en el que busco establecer vínculos entre categorías transdisciplinarias que permitan comprender los juegos políticos.

${ }^{3}$ El concepto de performatividad utilizado en este trabajo es el concepto clásico de la teoría del lenguaje del pensador inglés J. L. Austin (1976), para quien hablar es hacer.
} 
de este vacío oculto.

El vacío es también de la democracia que reaparece como una especie de "causa perdida" (Grüner, 2002, p. 22). No juega otro papel que el de servir como un espectáculo descolorido de un ritual vacío. También se convierte en el significante vacío (Laclau y Mouffe, 1985; Laclau, 2011) usado incluso por el extrema-derecha. En ese sentido, se podría decir que la democracia se convierte en algo de naturaleza espectral. Se borra en el momento en que se utiliza como reproducción y auto-realización inmediata del poder o de lo que, en Adorno, es la realidad misma como ideología (1973) y que se refiere al tema de la transparencia presente en la alegoría de la ropa nueva del rey. ${ }^{4}$ La ropa nueva del rey que no puede ser vista como ausente precisamente porque no existe, y por lo tanto debe ser aceptada como una fantasía colectiva con valor de verdad absoluta. Esta es la dimensión estética del populismo, el acuerdo de todos en torno a una mentira, que se confunde con su dimensión social.

La dimensión estética, en ese sentido, no es una fuerza o una cualidad de poder. Es el poder en sí mismo como un significante vacío expuesto en las inexistentes ropas del rey. Se puede decir que cuanto menos estético -en el sentido de buscar efectos- sea el carácter del poder, menos autoritario será. $Y$, en este sentido, no es sorprendente que el capitalismo sea una dictadura estética que busca a toda costa ocultar su carácter autoritario a través de la seducción y la adulación de las masas. Tal es el escenario en el que se desarrolla el juego del Ridículo Político.

Foucault mencionó lo ridículo como una característica de ciertos personajes ligados a la dimensión de lo "grotesco" ${ }^{5}$ que a su vez forma parte de la mecánica del poder. En su curso sobre Los Anormales, afirma que ya se podía percibir en personajes como Nerón y Heliogábalo

\footnotetext{
4 "La ideología contemporánea es el estado de conciencia y no conciencia de las masas como espíritu objetivo, no los productos mezquinos que imitan ese estado y lo repiten, para peor, para asegurar su reproducción. La ideología, en sentido estricto, tiene lugar donde se rigen las relaciones de poder que no son intrínsecamente transparentes, mediadas $y$, en este sentido, incluso atenuadas. Pero por todo esto, la sociedad actual, erróneamente acusada de excesiva complejidad, se ha vuelto demasiado transparente. Esta transparencia es precisamente lo que se admite con más reticencia. Cuanto menos ideología haya y más groseros sean los productos que la sucedan..." (Adorno y Horkheimer, 1973).

${ }^{5}$ Foucault aborda la relación entre verdad y justicia y afirma que es precisamente en la intersección de estas afirmaciones donde surgen los verdaderos discursos, con "efectos judiciales deseables" y que tienen la curiosa propiedad de ser ajenos a todas las reglas, incluso a las más elementales de un discurso científico, a las normas de derecho y que son "grotescas". (Foucault, 1999, p. 12; 1974, pp. 1406-1514). Le debo a Bertrand Ogilvie advertir de este texto de Foucault. Véase también: Sociedade Sem Lei. Pósdemocracia, personalidade autoritária, idiotização e barbárie de Casara (2018).
} 


\section{Marcia Tiburi}

el funcionamiento del personaje "ubuesco", expresión utilizada desde la obra Ubu Rei, de Alfred Jarry, puesta en escena a finales del siglo XIX en Francia. Foucault insiste en que es necesario tratar lo grotesco como una categoría de análisis y no como un mero insulto. Su intención es entender el "discurso grotesco", al mismo tiempo "estatutario e inhabilitado" ejercido por jueces y médicos en el contexto de producir un "efecto de poder". Foucault plantea la cuestión del "soberano infame", un personaje en su conjunto "infame, grotesco, ridículo", y de la "soberanía grotesca" definida por la "maximización de los efectos del poder a partir de la descalificación de quien lo produce" (Foucault, 1999, p. 11). ${ }^{6}$

En vista de la afirmación de Foucault de que la teoría de la "infamia del soberano" nunca se ha hecho, ha llegado el momento ${ }^{7}$ de investir menos en esta posibilidad que en el problema planteado por la cuestión. ¿Es posible contar la historia de los viles soberanos, la historia de los actores políticos vergonzosos por su violencia, estupidez, idiotez cuando lo que define el poder no es más que la forma de violencia que esconde lo grotesco y se utiliza en este proceso de trucos estéticos, tanto discursivos como imaginativos? Aunque Foucault no ha retomado la teoría del soberano infame, no se puede pasar por alto su potencial iluminador, sobre todo en un momento en que los ejemplos de los personajes y discursos grotescos proliferan en la escena política de todo el mundo. El texto que sigue busca ser una comprensión del escenario general, del estilo político al que las poblaciones están estética y políticamente sometidas y, a menudo, en plena alegría de esta condición.

En este texto, la elección de desarrollar el tema del ridículo, cuya especificidad debe ser analizada más allá de lo grotesco, se debe ${ }^{8}$ a la hipótesis que es la risa la que está en el centro de la operación estética del poder autoritario en su fase actual. Un análisis de lo grotesco implicaría otras investigaciones y otros alcances. Analizar la risa como un aspecto central de la

\footnotetext{
6 "En montrant explicitement le pouvoir comme abject, infâme, ubuesque ou simplement ridicule, il ne s'agit pas, je crois, d'en limiter les effets et de découronner magiquement celui auquel on donne la couronne. II me semble qu'il s'agit, au contraire, de manifester de manière éclatante l'incontournabilité, l'inévitabilité du pouvoir, qui peut précisément fonctionner dans toute sa rigueur et à la pointe extrême de sa rationalité violente, même lorsqu'il est entre les mains de quelqu'un qui se trouve effectivement disqualifié." (p. 11)

7 "Ce problème de l'infamie de la souveraineté, ce problème du souverain disqualifié, après tout, c'est le problème de Shakespeare; et toute la série des tragédies des rois pose précisément ce problème, sans que jamais, me semble-t-il, on ait fait de l'infamie du souverain la théorie." (p. 23).

${ }^{8}$ Como es una categoría amplia que aparece en otros escenarios con una multiplicidad de sentidos y riquezas que nos desviaría del foco al que el ridículo nos permite llegar con mayor precisión. Me refiero al libro Lo grotesco, un estudio de los significados de Barasch (1971).
} 
Ridículo político: análisis de una mutación estético-política.

dimensión estético-política debería ayudarnos a comprender el movimiento a través del cual una cierta imagen de la política vigente en el imaginario de la sociedad ha sufrido transformaciones dramáticas.

El concepto de Ridículo Político se refiere a un escenario, un ambiente o atmósfera pública. Los personajes que se presentan como caricaturas, y sin ninguna vergüenza de serlo, dentro de una industria de la comunicación manchada por la mentira y las noticias falsas, representan una especie de nuevo capital político que se ha producido y consumido ampliamente en la época de la política reducida a la publicidad como ya fue el caso en el período del nazismo alemán. La degradación de la política a la publicidad ha producido una especie de imagen, la de la política como mercancía. La imagen de la política profesional ejercida por los representantes parlamentarios es una imagen sin valor ético y moral. Esta imagen combina el moralismo, la religiosidad y la retórica del odio, que poco a poco y según las necesidades, hacen una transición al discurso fascista abierto. Los grotescos discursos de los que habla Foucault se encaminan hacia la destrucción y la muerte en los regímenes autoritarios, sin embargo, en un primer momento las poblaciones afectadas por tales discursos no toman en serio, o lo hacen poco, lo que dicen los portadores del discurso del odio, precisamente porque no entienden su contenido o, al entenderlo, piensan que son puras flatus vocis. Estos personajes políticos son considerados exagerados, caricaturescos, en una palabra, grotescos y/o ridículos, pero al mismo tiempo, ellos son divertidos. Se hacen merecedores de votos y victorias electorales por varias razones, como la venganza y el resentimiento de los votantes contra los políticos de izquierda?

Por Ridículo Político podemos, por lo tanto, definir tanto el rendimiento particular de un individuo como la performatividad en sí misma, una especie de método al que cualquiera grupo, movimiento, partido- puede adherirse. La calidad de la publicidad es la garantía de un beneficio político inmediato en forma de votos. La performatividad personal tiene lugar en una escena, una atmósfera construida, una especie de atmósfera dentro de un escenario en el que el actor sólo necesita ser espontáneo y catártico, en el que la estupidez, la rudeza, la tontería sirven de impulso para que el texto verbal sea entregado. En este escenario, que tiene la dimensión de un todo en la percepción colectiva, se establece una Gestalt de personajes

\footnotetext{
${ }^{9}$ Véase la investigación de Pinheiro-Machado, R. y Mury Scalco, L. (2020) y el libro Amanhã vai ser maior de Pinheiro-Machado (2019). Ver también la investigación de Solano Gallego, E. (2019) La bolsonarización de Brasil.
} 
políticos. La percepción de la forma política como algo desagradable que puede surgir para algunos espectadores no excluye el éxtasis generado a nivel escénico para masas enteras por tales personajes. Existen, en Brasil y en el mundo, casos de personas que podrían haber sido víctimas de escenas ridículas en las que participaron, pero que, de hecho, fueron recompensadas por ellas al elegirse a sí mismas como los candidatos más votados. ${ }^{10}$

El Ridículo Político se ha convertido en un capital estético-político. Se trata del retorno de algo arcaico, de una imagen que sobrevive en el tiempo para componer, bajo nuevas condiciones tecnológicas, un entorno en el que la política da espacio a una simulación específica de la barbarie. Es la política como el teatro de lo grotesco por lo ridículo. Podemos hablar de una inversión de los niveles éticos o morales, pero se trata de evaluar algo anterior, relacionado con lo que, en palabras de Adorno y Horkheimer, es el fascismo, cuando "lo que estaba oculto aparece a la luz del día", en el momento en que "la historia también se revela en su conexión con este lado nocturno e ignorado tanto en la leyenda oficial de los estados nacionales como en su crítica progresista" (1984).

Este fenómeno se hace aún más complejo en el contexto de una sociedad de espectáculo o de una sociedad excitada. Los votantes, individuos que potencialmente podrían ejercer una ciudadanía crítica, han sido reducidos a espectadores ${ }^{11}$, los robots de la política, transformados en puro espectáculo. Esto significa que la relación que los ciudadanos tienen con la política hoy en día está mediada por prácticas estéticas y tecnológicas que cambian la calidad

10 Hay varios casos, pero podemos destacar algunos miembros que merecen ser analizados: Tiririca, Janaína Pascoal, Alexandre Frota, Kim Kataguiri. Ascendieron al poder desde posturas que encajaban con lo que Foucault llamaba grotesco. Desafortunadamente, los detalles de cada uno de estos personajes no pueden ser analizados en el contexto de este artículo. Me refiero, sin embargo, a los congresistas que durante la famosa escena en el Congreso Nacional Brasileño, en el momento del voto de destitución de Dilma Rousseff en 2016, que conmocionó a la población. Los diputados que estaban allí fueron reelegidos en 2018. Uno de ellos, que pronunció el siguiente discurso, el más grotesco de todos, se convirtió en presidente de Brasil: "En este día de gloria para el pueblo brasileño, tiene un nombre que pasará a la historia en esa fecha, por la forma en que realizó su tarea. Felicitaciones, Presidente Eduardo Cunha. Perdieron en 64, perdieron ahora en 2016. Por la familia y la inocencia de los niños en el aula que nunca tuvo el PT, por el comunismo, por nuestra libertad, por el foro de São Paulo, por la memoria del coronel Carlos Alberto Brilhante Ustra, por el miedo a Dilma Rousseff, por el ejército de Caxias, por nuestras fuerzas armadas, por un Brasil por encima de todo y por Dios por encima de todo, mi voto es si". Bolsonaro era conocido por no haber hecho nunca una ley. Entre sus proyectos presentados a la cámara legislativa está el de la castración química de violadores. A pesar de su pobre desempeño en la Cámara, siempre ha sido uno de los más votados del país. El gobierno de Bolsonaro sigue hoy la línea de su campaña, que ha crecido y aparecido desde ese momento.

${ }^{11}$ Me esforcé por sentar las bases de una teoría de la televisión, en el libro Olho de Vidro: a televisão e o estado de exceção da imagem (2011) en el que trato de mostrar cómo la televisión es el universo de pantallas a las que estamos sometidos y que funcionan como un mecanismo de desubjetivación. 
Ridículo político: análisis de una mutación estético-política.

de las antiguas percepciones y rituales que definían, hasta entonces, la experiencia con la política.

Sin embargo, antes de proceder a este análisis, es necesario comprender el marco conceptual, epistemológico e histórico de la relación entre la estética y la política.

\section{El deslizamiento de la tragedia a la farsa}

Con la declaración de Marx en el Brumario $18^{12}$ que la historia una vez se presenta como tragedia y luego se repite como farsa, el terreno del Ridículo Político se presenta una vez más. Tal posición, leída por muchos como simple civismo, se refiere a un modelo trágico de política que habría sido adulterado. En Grüner, encontramos el tema del recurrente "deslizamiento de la tragedia a la farsa" (Grüner, 2002, p. 16), pero el autor no aclara cómo se lleva a cabo la operación de deslizamiento. La pista está en el modelo marxista: los personajes del presente serían imitaciones caricaturescas de héroes del pasado. La operación es estética: la imitación o mímesis, que, desde la controversia entre las posiciones de Platón y Aristóteles, implica la falsificación, en la primera; mientras que, en la segunda, implica la ficción. ${ }^{13}$ En Platón, la mímesis no se refiere sólo a las obras de arte, sino a todos los seres, incluyendo los discursos e instituciones. Platón será un crítico del procedimiento mimético, ese artificio imitativo por el cual las ideas que habitan un mundo más allá de lo sensible están como manchadas en forma de simulaciones, un problema que no se encuentra en Aristóteles. La preocupación de Platón es con la experiencia formativa, con la educación, mientras que Aristóteles habría sido más condescendiente con la dimensión de entretenimiento propia de las artes imitativas. Para los fines de este argumento, es importante saber que la mímesis es un concepto que implica un método, un movimiento entre las ideas y la realidad, análogo al sentido de Eros en el campo del conocimiento como vemos en el Banquete (Platón, 2002).

La perspectiva de Aby Warburg ${ }^{14}$ ayuda a entender esta idea de un deslizamiento entre la tragedia y la farsa a través del cual la intimidad entre la estética y la política se hace evidente.

\footnotetext{
12 "Hegel observa en una de sus obras que todos los hechos y personajes de gran importancia en la historia del mundo ocurren, por así decirlo, dos veces. Y se olvidó de añadir: la primera como tragedia y la segunda como farsa." (Marx, 2011, p. 6)

${ }^{13} \mathrm{El}$ concepto de mímesis recorre la historia de la estética filosófica, siendo el arte y la literatura uno de sus términos más polifónicos. Ver Gebauer, G. y Wulf, C. (1996).

${ }^{14}$ Warburg, A. (2017; 2003) y Michaud, P-A. et Didi-Huberman, G. (2012)
} 


\section{Marcia Tiburi}

Grüner percibe esta intimidad en la obra de Aby Warburg, un investigador que se ha convertido en importante para el mundo de la historia del arte, pero cuya dimensión política rara vez se observa. Grüner percibe en la "dualidad siniestra (unheimliche Doppelheit) del hecho cultural" (unheimliche Doppelheit) entre el terror y la belleza, entre el caos y la armonía, la relación entre la tragedia y la política. La noción de dualidad siniestra está relacionada con la noción de Freud de extrañeza inquietante. Es posible ampliar esta noción para entender la relación entre la tragedia y su par estético habitual, la comedia. Al igual que la tragedia, la comedia no es sólo un estilo, o una forma, en el sentido de un género literario o teatral sino, sobre todo, una cierta manera de articular la política.

En este sentido, la operación de deslizamiento no implica el fin del ritual político, sino la aparición de otro ritual, aquel dentro del cual ya no es la vida de los dioses y la trascendencia lo que está en juego, sino la animalidad del ser humano. Si la tragedia hace reír, la comedia hace que la risa sea imperativa. En otro nivel de comparación, se puede decir que en lugar de lo bello y sublime que constituye el campo de la tragedia, lo que hay en el campo de la comedia es el asco, lo siniestro y la sensación de distopía. La tensión entre el consciente y el inconsciente que se juega en el universo del cómico vuelve a poner en escena la "siniestra dualidad" en una eterna repetición del deslizamiento introyectado y transformado en operación mental. Los procedimientos de cultivo son procedimientos subjetivos. La comedia implica el ritual carnavalesco en el que se invierten los sentidos habituales, pero que pueden ser vividos subjetiva e individualmente. Hay en la comedia una destrucción formal de la ley previamente establecida que en la tragedia fue tensionada y problematizada, pero aun así respetada. La siniestra dualidad implica un movimiento de basculamiento dialéctico. La comedia se convierte en terror y, más allá, en fascismo.

Es con Warburg que la posibilidad de una historia de las imágenes surge de la hipótesis que hay una supervivencia de estas imágenes en el tiempo histórico, que regresan en el tiempo. El término usado por Warburg es "nachleben". Eduardo Grüner vio en el "nachleben" de Warburg la idea de una "supervivencia zombi" que en todo se combina con el momento político de las naciones dominadas por tiranos fascistas. El deslizamiento frente a esta observación tendría que ver con el deterioro, con el proceso de muerte. Sería el instinto freudiano de muerte o la represión (Verdrängung), sería la decadencia nietzscheana, o sería mucho más un proceso por el cual la sublimación que debería haber ocurrido en la tragedia como obra de arte, se convierte en fantasmagoría en la comedia como Fake News. 
El deslizamiento al que se refiere Grüner implica que la política (la burocracia) destruye lo Político (el universo de Zôon Logikon). De la misma manera, la estética estaría destruyendo la estética, así como lo cómico estaría aplastando la tragedia. La fórmula por la cual la industria cultural es para la burocracia, como la política para el político, tiene valor en este proceso. Es la política misma la que vuelve vacío su funcionamiento y aparece con la farsa, como forma pura, como emulación pura sin contenido, como "poder sin cualificación", como el sujeto de Ubu Roi y no de Macbeth (siendo uno la continuidad del otro), en el momento en que la política se imita a sí misma, se simula a sí misma y el mundo parece duplicado y, en momentos catastróficos, incluso invertido. El paso de la tragedia a la farsa es una constante, un basculante en el que la intersección entre la estética y la política constituye su vínculo. La sensación actual del siniestro freudiano en la experiencia política, la tragedia y la farsa marxista, la supervivencia zombi encarnada por los personajes políticos de nuestro tiempo no nos permiten olvidar el estupor paralizante de los pueblos indígenas ante los comedores de oro españoles de los que habla Silvia Cusicanqui $(2010)^{15}$. Tales ejemplos forman parte de la misma experiencia estético-política de los pueblos que nunca deja de repetirse.

Potenciado por los medios de comunicación y el avance de la esfera digital, el ridículo da una imagen popular al poder, una imagen cuya función es producir adulación para la producción de identificación con el líder y así promover el vínculo, el lazo irreductible entre el

\footnotetext{
${ }^{15}$ La sensación de que el mundo está invertido, sin embargo, no es nueva en términos de política. Ya había golpeado a los pueblos amerindios hace mucho tiempo. Ahora puede convertirse en una categoría de análisis político también para todas las culturas amenazadas en esta etapa de nuestra historia. Según la filósofa boliviana (Cusicanqui, 2010): "La lengua en la que escribe Waman Puma está plagada de palabras y giros de habla oral en qhichwa, de canciones y jayllis en aymara y de nociones como "Mundo al Revés", que se derivan de la catastrófica experiencia de la conquista y la colonización. Esta notación de Mundo al Revés salió a la luz en la obra de un pintor que investigó las mediaciones del siglo diecinueve, que en su desafortunada vida política como hombre confinado y deportado, aprendió a conocer los lugares más recónditos del país y a convivir con los indígenas de los que sólo se notaban - como los Bororos en el lgnacio o los Chacobos y Moxeños en las tierras orientales. Para él, el Mundo al Revés aludía al gobierno de la república, en manos de bestias, que uncen al pueblo de trabajo el arado de los bueyes." En la sociología de las imágenes de Cusicanqui, encontramos la cuestión del mundo invertido, de un mundo al revés, el mundo de los pueblos invadidos por los españoles y humillados por ellos. Cusicanqui muestra la operación de "apequeñamiento" de los indios registrada en las imágenes de Waman Puna, de las que cree que es posible rehacer la historia del sometimiento de los pueblos, incluyendo los aspectos psicológicos implicados en los procesos de humillación. En este caso, la violencia era un operador de destrucción, que los rituales de los pueblos indígenas vienen a rehacer la relación entre el "Estado" indígena, lo social y el ritual, en un momento dado, reposicionando el sentido de la muerte y la violencia vivida. Si Warburg analiza la repetición de imágenes en el tiempo, sopesando lo estético, Cusicanqui hace lo mismo, pero sopesando lo político. Si la operación de Warburg es política, como dice Grüner, la de Cusicanqui es estética.
} 


\section{Marcia Tiburi}

líder y sus seguidores. Las masas están complacidas, no sólo por las imágenes con las que pueden sentirse contempladas narcisistamente, sino a un nivel más profundo, físicamente (Türcke, 2010), como veremos a continuación.

\section{La risa como catarsis en el contexto de la industria cultural}

En el imaginario popular, la política es un concepto cada vez más asociado a la farsa que es, técnicamente hablando, una forma teatral del orden de la comedia, pero que también tiene un sentido de mala calidad, de engaño. La forma general de la farsa asumió el todo del ritual político y se convirtió en la imagen general de la política. Se trata, pues, en el texto actual, de comprender las operaciones vinculadas a la risa -y a lo cómico en contraposición a lo trágicoque ponen de manifiesto las formas de soberanía infame, para aprovechar la expresión de Foucault, que debemos comprender en el momento en que resurge en nuevas condiciones, presentándose como la reproducción del caos en la dirección opuesta a la cohesión necesaria para sostener una sociedad.

En el escenario de la alabanza abstracta a la libertad de expresión, en sí misma objeto de mistificación por las técnicas de comunicación comunes al campo de la extrema derecha que la reduce a lo que podemos definir como neoliberalización del lenguaje, la crítica de la risa sucumbe fácilmente a la fama de autoritarismo, tal es el predominio de la ideología neoliberal en todas las mentes que organizan una verdadera colonización neoliberal de las ideas. Considerado un valor en un lugar como Brasil, donde prevalece la imagen del país de los chistes preparados, la risa es un tema que requiere una reflexión crítica. Adorno y Horkheimer son autores que se dedican a un análisis crítico de la risa. En el texto sobre la Industria Cultural encontramos eso:

"En la falsa sociedad, la risa ha atacado -como una enfermedad- la felicidad, arrastrándola a la indigna totalidad de esa sociedad. Reírse de algo (Lachen) es siempre ridiculizar (Varlachen), y la vida que, según Bergson, rompe con la risa la consolidación de las costumbres, es en realidad la vida que estalla bárbaramente, la autoafirmación que se atreve a celebrar en una ocasión social su liberación del escrúpulo." (1988, p. 147) 
Ridículo político: análisis de una mutación estético-política.

Los autores señalan la continuidad entre la risa y el ridículo, el acto o hecho particular de la risa y la acción que la promueve hacia el otro. Esta acción quita la simple naturalidad o espontaneidad de la risa y la coloca en un lugar político, mediado por las relaciones de poder. Tomar la risa de antemano como una virtud o una ventaja es el peligro que la cultura se ha acostumbrado a correr hasta que este peligro se vuelve natural. Esto es precisamente el uso de la risa en una cultura autoritaria.

La crítica de la risa de Adorno y Horkheimer forma parte de una crítica estética, a saber, la crítica de la belleza como una especie de forma ideológica resultante de una "reproducción mecánica de la belleza" como una "exaltación reaccionaria de la cultura". Los autores hablan de un "triunfo sobre la belleza" que se lleva a cabo por medio del humor, como en una guerra en la que se ataca a lo elevado, lo trágico, lo trascendente. Los autores tienen una visión dialéctica de este juego de fuerzas, pero no consideran la risa como una victoria. Tampoco es la belleza sobre la cual se pretende triunfar. La risa es una falsa victoria. En este sentido, afirman que "nos reímos del hecho de que no hay nada de lo que reírse" (1988, pp. 148-149). La risa se ha convertido en una forma de engañar a la felicidad, lo que sería un parámetro ético de la cultura. En este sentido, vemos en tal proceso el método de degradación y reversión que es propio de la comedia como estructura artística.

La risa y la acción del ridículo están en el corazón de la operación de fascistización de la cultura. La fascistización es un proceso que funciona como un juego de lenguaje. En ella, la catarsis no indica la purificación de las pasiones negativas, sino el vaciamiento de la subjetividad. La catarsis es perpetrada por el capitalismo que domina todas las esferas de la vida, incluyendo la política. La actuación del que imita al clown, sabiendo o no que lo hace, está ahora mucho más cerca del kitsch considerando las condiciones históricas del propio capitalismo, la moda, el estilo y la creación de patrones plásticos. Es en este sentido que Adorno dirá en Teoría Estética que "kitsch parodia la catarsis" (p. 268).

La risa ha sido aplastada. En la pérdida de su carácter crítico e inquietante, se ha transformado en simple y puro entretenimiento como es el caso de las formas lingüísticas bajo el signo de la Industria Cultural. La risa que podía ser crítica preparó el camino para el libertinaje superficial y el cinismo. Si fuera la risa de la reconciliación, si fuera la risa del terror, la primera para liberarse de los "peligros físicos" y la segunda de las "garras de la lógica", lo que uno esperaría con la risa sería una liberación más profunda. Los filósofos de Frankfurt dirán que "la liberación prometida por la diversión es la liberación del pensamiento como negación" (p. 


\section{Marcia Tiburi}

153 $)^{16}$. Es en este sentido que el entretenimiento será, para los autores, la nueva catarsis. (Veloso, 2018) La "industria cultural devela la verdad sobre la catarsis" (p. 152) ${ }^{17}$ porque si "la catarsis es una acción purgativa de las emociones que armoniza con la represión" (Adorno, s/d. p. 267) esto significa que encuentra nuevos caminos de expresión no siempre ligados a algo mejor.

El trote social implícito en la risa, como vemos en Bergson, implica algo de esta catarsis y el carácter estético-político de la risa. Según él,

[e]l placer de reír no es un placer puro, me refiero a un placer exclusivamente estético, absolutamente desinteresado. Se mezcla con una segunda intención que la sociedad tiene hacia nosotros cuando no nos tenemos a nosotros mismos. La intención no confesada de humillar está mezclada, así que es cierto, de corregir todo al menos externamente (Bergson, 1959, p. 61).

En este caso, la risa implica una acción sobre el otro que es la de la humillación, de la degradación que garantiza una especie de soberanía, la de la superioridad subjetiva en un breve juego de lenguaje, como el chiste. En un nivel institucional, implicaría la superioridad del gobernante malvado, que humilla al pueblo y es, por el pueblo, idolatrado. En contextos de polarización, el pueblo humilla al pueblo con el infame líder como mediador de la humillación. La catarsis está en este caso vinculada a una operación por la cual se ha perdido de vista lo trágico. Bergson se dio cuenta de la proximidad del campo de la risa a la vida. En sus palabras:

la comedia está mucho más cerca de la vida real que el drama. Cuanto mayor es el drama, más profunda es la elaboración a la que el poeta tuvo que someter la realidad para comprender la tragicidad en estado puro. Por el contrario, sólo en sus formas más bajas, el vodevil y la farsa, la comedia contrasta con la realidad, pues cuanto más se eleva, más tiende a confundirse con la vida, y hay escenas de la vida real

\footnotetext{
16 "Die Befreiung, die Amusement verspricht, ist die von Denken als von Negation."

17 "Wie über den Stil enthüllt die Kulturindustrie die Wahrheit über die Katharsis."
} 
Ridículo político: análisis de una mutación estético-política.

tan cercanas a la alta comedia que el teatro podría apropiarse de ellas sin cambiar una palabra. (Bergson, 1959, p. 61)

La comedia imita la realidad -mientras que la tragedia en la definición clásica de Aristóteles (2013) imita el mito- en un nivel diferente. A veces, llegando a lo escatológico, como en los conceptos de bajo material y corporal en Bakhtin (2010, p. 323). El elemento autoritario de la risa está ligado a una disminución no dialéctica de los valores de lo trágico. Lo que vale en términos del dicho latino castigat ridendo mores, es decir, reírse y "castigar" las costumbres, cambia absolutamente cuando se trata del ridículo contemporáneo que se ha convertido en un patrón hegemónico, dando a todo ese aire de similitud del que hablaban Adorno y Horkheimer en relación con la industria cultural. Si, como dijo Bakhtin, "El bufón es el rey del mundo al revés" (p. 325), se ha reproducido tecnológicamente y publicitariamente hasta que no hay más diferencias entre los mundos.

La imagen de bufonada política que aparece en profusión en las noticias, desciende de una especie de tergiversación de los aspectos cómicos. Históricamente, el carnaval tenía la función política de igualar a las clases inferiores, de relativizar las verdades, de poner a las autoridades en un lugar humano adecuado, creando lo que en opinión de Bakhtin (2010, p. 14) fue uno de los momentos más fundamentales del humanismo, aquel en el que las personas podían vivir una intensa relación entre la utopía y la realidad mediante la cancelación de las desigualdades. Para Bakhtin, la degradación es un principio topográfico, corporal y material que no tiene un aspecto moral abstracto.

Si la lógica de la visión carnavalesca del mundo era la de las cosas al revés, de un mundo en el que todo estaba invertido, tenemos un parámetro a partir del cual podemos pensar en el ridículo político contemporáneo. No se trata, en ridículo, de crear un segundo mundo, una segunda vida, como en el carnaval, en el que toda puesta en escena busca y conduce a una especie de desorden, es un mundo a la baja en el que la segunda vida tomó el lugar de la primera, en el que lo serio y lo no serio se confundieron, en forma de yuxtaposición de escenas que pueden producir efectos altamente destructivos de la subjetividad y la objetividad. En este sentido, la risa es la trampa, el cebo que la Industria Cultural pone a las hordas de consumidores devorados por el consumismo. 


\section{Marcia Tiburi}

\section{Sociedad políticamente excitada}

El concepto de la risa como catarsis nos ayuda a entender la adhesión de las masas al fascismo. Por un lado, la banalidad se apodera de todos los procesos y experiencias sociales y comunitarias. Por otro lado, la banalidad lleva al éxtasis. La catarsis en la industria cultural tiene este papel de narcótico. Es la percepción humana que se ve afectada bajo condiciones estéticas la que, en nuestra época, comprende los medios microtecnológicos, digitales y mediáticos como se expone en la obra de Christoph Türcke Sociedad Excitada (2002; 2010) en la que el carácter extático de los medios se apodera del mundo de la vida. Estas condiciones definen la producción del lenguaje y su difusión. Las condiciones de nuestra época involucran a la industria cultural en su conjunto, pero también a la industria cultural de la política, lo que nos lleva a reflexionar sobre la creación de estereotipos políticos que son exitosos, que causan sensación. Son actores políticos que, como stars, hipnotizan a las masas poniendo a todo el mundo bajo el efecto de sus discursos y actuaciones. La hipnosis y la producción de éxtasis se convierten en metodologías políticas. No es casualidad que la religión, la economía y la política se acerquen cada vez más porque utilizan métodos similares.

La sociedad de la "sensación" de la que habla Türcke es aquella en la que el control de los cuerpos se ejerce a nivel de la estimulación de la percepción mediante una estrategia de choques a diversas intensidades. ${ }^{18}$ Los choques actúan sobre los sentidos y sobre toda la sensibilidad de los individuos cuya capacidad de percepción no puede ser descuidada en una vida definida por las condiciones digitales. Para Christoph Türcke la sensación es un nuevo paradigma $^{19}$ cuya historia debe ser entendida. Türcke habla de una cultura en la que las condiciones microtecnológicas determinan la experiencia. Según él, hay un debilitamiento de lo que él llama "sentido teológico y político de lo que "necesariamente nos golpea". El proceso es "fisiológico", es decir, toca no sólo la racionalidad o la sensibilidad (categorías que tratan el cuerpo humano de manera dualista), sino el "sentido fisiológico de la expresión".

Si, de hecho, la percepción de lo que produce sensación se convierte en la "sensación

\footnotetext{
${ }^{18}$ Naomi Klein (2008) reconstruye la historia de la investigación de las descargas eléctricas en los Estados Unidos y el uso del mecanismo en la tortura en la época de las dictaduras latinoamericanas y compara el neoliberalismo como un procedimiento basado en una política de descargas.

19 "Desde cierta perspectiva, el paradigma de la sensación es más "paradigmático" que el concebido por Kuhn: no sólo como la base de investigación de un sistema científico, sino como la base de percepción de toda una sociedad. No sólo las creencias científicas están sujetas a cambios históricos; todo el aparato de percepción, del que emergen, se transforma, sólo que mucho más lentamente." (Türcke, p. 85)
} 
Ridículo político: análisis de una mutación estético-política.

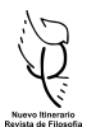

tout court", todos los cuerpos se someten a ella. La sumisión a la sensación como forma de excitación es estética y política. Altera el campo de la política y la estética, así como las prácticas estéticas y políticas del mundo de la vida. Lo que causa "sensación" es una farsa. La calidad de esta sensación, a su vez, dependerá de factores vinculados a las condiciones culturales de los individuos y grupos. La comedia llegará más fácilmente a las masas cuyas subjetividades han sido configuradas durante mucho tiempo para las actuaciones cómicas y la catarsis de la industria cultural. El estilo es kitsch. En este sentido, los diputados más votados en las elecciones de países como Brasil son los que hacen reír a la gente, o los que capturan a los votantes por gracia. El mismo Jair Bolsonaro, antes de convertirse en un fascista más serio, era visto sólo como un tipo jocoso. Muchos intelectuales no creyeron en su potencial hasta justo antes de las elecciones. Hay algo ficticio en el fascismo (Adorno, 2019, p. 13). La propaganda como máquina de guerra es el campo responsable del trabajo de convertir el ridículo en algo "sensacional".

En vista de la degradación de la política a la publicidad, podemos entender por qué ciertos gobernantes electos en la ola del extremismo de derecha no parecen tener la competencia para gobernar, sino que continúan en acción como si todavía estuvieran en campaña, en pleno ejercicio de la retórica verbal y visual de la propaganda como se puede ver en las manifestaciones de Trump y Bolsonaro en las redes sociales incluso después de haber ocupado sus puestos. Es la lógica de la típica pieza comercial de la campaña política que se ha convertido en método. En este sentido, la política puede definirse como una mercancía en el

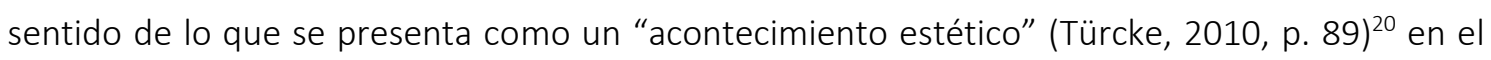
que lo comercial es "la nueva forma de comunicación y percepción". Estamos impulsados por una "alta presión" de información que es a la vez económica, estética y fisiológica.

El cuerpo es golpeado por choques que funcionan como inyecciones que dominan la existencia físicamente a través de un circuito en el que se manipulan la anestesia y la adicción. El desgaste del sistema nervioso vendrá más tarde. Antes, el cuerpo se acostumbrará al juego entre el placer y el disgusto y permanecerá vivo y, para recordar a Foucault, será un cuerpo dócil. A través de la sensación, este cuerpo es explorado económica, física y estéticamente.

\footnotetext{
20 Según Türcke: "La presentación de los bienes es siempre un evento estético también. Las cosas que ya vienen al mundo como mercancía y por lo tanto tienen que ser preparadas para el mercado ya durante la fabricación están provistas de una superficie brillante. Con esto la producción de bienes trae consigo la necesidad interna de una tecnología de configuración de toda la superfície." (p. 189)
} 


\section{Marcia Tiburi}

Türcke dirá que "la estetización de todas las relaciones de producción y de vida es también una estetización de la expropiación y de la explotación" (p. 268). Es en este sentido que los "shocks audiovisuales" aplicados a los cuerpos como "golpazos" hacen que "la caja registradora suene en alguna parte" y nadie se da cuenta de que están siendo explotados porque son adictos a la moda, a las series de televisión, a las redes sociales.

El abuso sobre el cuerpo es el verdadero motor de la economía capitalista. No hay que olvidar la relación con la historia de la explotación de la mujer, y la centralidad del cuerpo en este proceso, como una explotación "económica, física y estética" al mismo tiempo y que es el modelo básico de explotación y violencia del capitalismo vigente hasta hoy. ${ }^{21}$

A partir de la exploración del sistema sensorial, el sistema nervioso en sí, pocos tienen la oportunidad de escapar. Uno de sus efectos es la "compulsión a emitir" que se convierte en un comportamiento universal. Tiene la estructura de la adicción que se convierte en algo banal ${ }^{22}$ y universal. La docilidad de los cuerpos es explícita en lo que Türcke define como la "característica esencialmente conformista de la adicción": la voluntad de un número colosal de seres humanos de colocarse ante el cuentagotas de un aparato multimedia y dejarse explorar neurológica y estéticamente. Este cuestionamiento nos ayuda a entender por qué presidentes como Jair Bolsonaro o Donald Trump y tantos otros personajes del Ridículo Político, y todo su gobierno, aplican diariamente choques a la población, con palabras y acciones lingüísticas. Tales choques son promovidos por las redes sociales. Su contenido llega a dominar las noticias diarias y la mentalidad. Las acciones relacionadas con la aniquilación de los derechos se esconden detrás de los titulares y escenas diarias de ridículo político que constituyen una nueva forma de totalitarismo internalizado por los ciudadanos y tal vez sin posibilidad de ser superado social, estética y políticamente.

El avance del Ridículo Político se basa en su propia naturalización. Las masas desprovistas de recursos caen en la retórica visual y verbal del ridículo, pero incluso la perplejidad de los intelectuales y estudiosos ante el fenómeno es una de las cualidades que éste produce y que constituye su fuerza. Todos son capturados por el carácter extático de la escena.

\footnotetext{
${ }^{21}$ Me refiero a la lectura del libro de Federici (2017) sobre el paso del feudalismo al capitalismo y el papel de la acumulación primitiva de capital sobre las mujeres, que mantiene hasta nuestros días.

${ }^{22}$ En un trabajo anterior desarrollé la noción de "banalidad del vicio". (Tiburi, M.; Dias, A., 2012)
} 
Ridículo político: análisis de una mutación estético-política.

El populismo de la extrema derecha navega tranquilamente en esta producción y reproducción del éxtasis, que se debe a su propia naturaleza.

La naturalización del ridículo es la mayor astucia del capital en una sociedad excitada. El ridículo se impone como capital y como nueva mediación. Ya no es la simple imagen o escena, sino la imagen capitalizada por su exceso, por su falta de medida, por su potencial de inversión. Tampoco es sólo una imagen vista como ficción o entretenimiento, es mucho más un éxtasis religioso-económico y político.

El ridículo político es una relación social mediada por escenas. Estas escenas son el espectacular, exhibicionista y ostentoso capital en sí mismo. La subjetividad implicada en este proceso es la del perverso, el sujeto sin la dimensión del otro y que, con él, está conviviendo. El uno para el que el otro no es el mismo, sino sólo un enemigo y, como tal, debe ser tratado como una cosa, o como un tonto en un juego cínico. Aquel que debe ser humillado y degradado mientras no puede percibirse a sí mismo como un objeto en un juego porque las condiciones que le permitirían saber que era un juego fueron extirpadas antes de que pudiera elegir participar en él. 


\section{Marcia Tiburi}

\section{Bibliografía}

Adorno, T. y Horkheimer, M. (2019) Aspekte des neuen Rechts-radikalismus. Berlim: Suhrkamp.

Adorno, T. y Horkheimer, M. (1973) Ideologia, en: Temas básicos da sociologia. São Paulo: Ed. Cultrix.

Adorno, T. y Horkheimer, M. (1988) Dialektik der Aufklärung. Frankfurt am Main: Fischer.

Adorno, T. y Horkheimer, M. (1984) Dialética do Esclarecimento. Rio de Janeiro: Jorge Zahar.

Adorno, T. (1982) Teoria Estética. Lisboa: Edições 70.

Agamben, G. (1984) Scienza senza nome. En Aby Warburg e la Scienza senza nome. Aut aut no 199-200, Florença, Nuova Italia, p. 58.

Aristóteles (2013) "Poetics." (Trad. S. Butcher) En The Project Gutenberg. Recuperado en http://www.gutenberg.org/files/1974/1974-h/1974-h.htm

Austin, J. (1976) How to do things with words. Cambridge: Harvard Press.

Bakhtin, M. (2010) A Cultura Popular na Idade Média e no Renascimento. O contexto de François Rabelais. São Paulo: Hucitec.

Bakhtin, M. (2010a) Sociedade excitada. Filosofia da sensaçao. Campinas: Editorial UNICAMP.

Barasch, F. (1971) Lo grotesco, un estudio de los significados. La Haya: Mouton.

Baumgarten, A. (1993) Estética. A Lógica da Arte e do Poema. Petrópolis: Vozes.

Bergson, H. (1959) "Le Rire. Essai sur la signification du comique." En Édition du centenaire des Oeuvres de Bergson (pp. 391-485). Paris: Les Press universitaire de France.

Casara, R. (2018) Sociedade Sem Lei. Pós-democracia, personalidade autoritária, idiotização e barbárie. Rio de Janeiro: Civilização Brasileria.

Cusicanqui, S. (2010) Ch'ixinakax utxiwa: una reflexión sobre prácticas y discursos descolonizadores. Buenos Aires: Tinta Limón.

D’angeli, C. y Paduano, G. (2001) Lo cómico. Madrid: La Balsa de la Medusa.

Debord, G. (2006) La Societé du Spectacle. Paris: Gallimard.

Federici, S. (2017) Calibã e a Bruxa. Mulheres, Corpo e Acumulação Primitiva. São Paulo: Elefante. 
Ridículo político: análisis de una mutación estético-política.

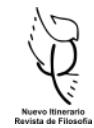

Fisher, M. (2009) Capitalist Realism. Hants: O Books.

Foucault, M. (2011) “La vérité et les formes juridiques." En: Dits et Écrits I. Paris: Gallimard.

Foucault, M. (1999) Les Anormaux. Cours au Collège de France, 1974-1975. Paris: Gallimard/Seuil.

Foucault, M. (1993) Surveiller et punir: Naissance de la prison. Paris: Gallimard.

Freud, S. (2012) Das Unheimliche. Bremen: Europäischer Literaturvlg.

Foucault, M. (2015) Der Witz und seine Beziehung zum Unbewußten / Der Humor. Hamburg: Sevérus.

Foucault, M. (1996) Os Chistes e sua relação com o inconsciente. Rio de Janeiro: Imago.

Gebauer, G. y Wulf, C. (1996) Mimesis, Culture, Art, Society. Berkeley: University of California Press.

Grüner, E. (2017) Iconografías Malditas, Imágenes Desencantadas. Hacia una Política "warburguiana" en la Antropología del Arte. Buenos Aires: EUFyL.

Grüner, E. (2002) La Tragedia, o el fundamento perdido de lo politico. Buenos Aires: CLACSO.

Grüner, E. (2006) "O Estado: paixão de multidões. Espinosa versus Hobbes, entre Hamlet e Édipo." En A. Borón, (pp. 145-167), São Paulo: CLACSO/DCP-FFLCH-USP.

Harvey, D. (1992) A condição pós-moderna. São Paulo: Loyola.

Jarry, A. (1896) Ubu Roi. Paris: Édition du Mercure de France.

Kant, I. (1968) Kritik der Urteilskraft. Frankfurt: Suhrkamp. vol. 10.

Klein, N. (2008) The Chock Doctrine. The rise of disaster Capitalism. New York: Picador.

Kojève, A. (1947) Introduction à la Lecture de Hegel. Paris: Gallimard.

Laclau, E. y Mouffe, Ch. (1985) Hegemony and socialista strategy. Towards a radical democratic politics. Londres: Verso.

Laclau, E. (1993) Nuevas Reflexiones sobre la revolución de nuestro tiempo. Buenos Aires: Nueva Visión.

Laclau, E. (2011) Emancipação e diferença. Rio de Janeiro: EDUERJ.

Lebrun, J-P. (2007) La Perversion Ordinaire: viver emsemble sans autrui. Paros: DeNöel. 
Marx, K. (2011) O 18 Brumário de Luís Bonaparte. São Paulo: Boitempo.

Michaud, P-A. (2012) Aby Warburg et l'image en mouvement. Paris: Mácula.

Mouffe, Ch. (2013) Agonistics. Thinking the world Politically. London/New York: Verso.

Pinheiro-Machado, R. y Mury Scalco, L. (2020) "From hope to hate: The rise of conservative subjectivity in Brazil." En HAU: Journal of Ethnographic Theory. V. 10.n. 1. https://doi.org/10.1086/708627

Pinheiro-Machado, R. (2019) Amanhã vai ser maior. São Paulo: Planeta.

Platón. (2018) "Le Banquet." En CEuvres complètes. Tome IV, 2e partie. Paris: Belle Lettres.

Solano Gallego, E. (2019) "La bolsonarización de Brasil." En Documentos de trabajo del IELAT, Versión Digital, № 121, abril. En el Instituto Universitario de Investigación en Estudios Latinoamericanos - Universidad de Alcalá.

Tiburi, M.; Dias, A. (2012) Sociedade Fissurada: para pensar as drogas e a banalidade do vício. Rio de Janeiro: Civilização brasileira.

Tiburi, M. (2017) Ridículo político: uma investigação sobre o risível, a manipulação da imagem e o esteticamente correto. Rio de Janeiro: Record.

Tiburi, M. (2011) Olho de Vidro: a televisão e o estado de exceção da imagem. Rio de Janeiro: Record.

Tiburi, M. (2019) Delírio do poder. Psicopoder e loucura coletiva na era da desinformaçao. Rio de Janeiro: Record.

Türcke, C. (2002) Erregte Gesellschaft. Philosophie der Sensation. Munchen: C.H. Beck.

Tiburi, M. (2010) Sociedade excitada: filosofia da sensação. Campinas: Editora da Unicamp.

Veloso, C. (2018) Pourquoi la "Poétique" d’Aristote? Diagogè. Paris: Vrin.

Warburg, A. (2017) Histórias de fantasmas para gente grande. Escritos, esboços e conferências. São Paulo: Companhia das Letras.

Warburg, A. (2003) Le rituel du serpente - Art \& Anthropologie. Paris: Ed. Macula. 